\title{
Seasonal development of spatial snow-depth variability across different scales in the Swiss Alps
}

\author{
Luca EGLI, ${ }^{1}$ Nena GRIESSINGER, ${ }^{2}$ Tobias JONAS ${ }^{1}$ \\ ${ }^{1}$ WSL Institute for Snow and Avalanche Research SLF, Flüelastrasse 11, CH-7260 Davos-Dorf, Switzerland \\ E-mail: egli@slf.ch \\ ${ }^{2}$ Department of Hydrology, University of Bayreuth, Universitätsstrasse 30, D-95440 Bayreuth, Germany
}

\begin{abstract}
The depth of snow cover is temporally and spatially heterogeneous at different scales in Alpine regions. For snow hydrology/climatology the spatial variability of snow depths is a key parameter for capturing the total amount of snow in a given area. Here a scale analysis of the spatial variability of snow depths during the accumulation period is investigated. The development of the variability is characterized by a parameter, $\beta$, describing the relationship between the standard deviation and the mean of snow depths. The analysis includes two datasets: (1) 141 snow-depth point measurements representing flat-field observations, and (2) snow precipitation from the numerical weather prediction model COSMO-7. The results reveal that $\beta$ is almost invariant at scales between 10 and $300 \mathrm{~km}$. The COSMO-7 data exhibit the same scale invariance above $50 \mathrm{~km}$, indicating that the spatial variability of snow depths is formed by the precipitation pattern at these scales. The scaling analysis of $\beta$ allows determination of the absolute accuracy of estimating the total amount of snow in a given area and helps to validate different snow models or remote-sensing techniques by ground truth verification.
\end{abstract}

\section{INTRODUCTION}

Snow depth, HS, and its spatial distribution is a key parameter in cold region sciences such as avalanche formation/dynamics (e.g. McClung and Schaerer, 1993), snow climatology (e.g. Marty, 2008) and snow hydrology (e.g. DeWalle and Rango, 2008). Particularly in snow hydrology, HS data can be used with a parameterization of the snow bulk density (Jonas and others, 2009) to monitor the seasonal development of mountain water resources (e.g. in the Swiss Alps). Particularly for flat-field HS measurements, the reliability of the simple parameterization of SWE with HS has been shown (Egli and others, 2009). Therefore, the scale analysis in this study focuses exclusively on snowdepth readings. If an area of homogeneous snow distribution can be found, a single point HS measurement is needed to capture the total amount of snow in that area. However, the snow cover is spatially highly variable (e.g. Shook and Gray, 1996). This makes it difficult to provide reliable estimates of the mean $\mathrm{HS}$ in a given region by $\mathrm{HS}$ point measurements exclusively or by different interpolation schemes (e.g. Erxleben and others, 2002). It also complicates validation of the estimates of remote-sensing techniques (Seidel and Martinec, 2004) or spatially distributed snow models (e.g. Luce and others, 1999; Liston 2004; Lehning and others, 2006).

Egli and Jonas (2009) reported that the spatial distribution of HS measured on high-Alpine flat sites exhibits a considerable heterogeneity at the scale of the entire Swiss Alps. In fact, it was shown that the variability of HS, quantified by the standard deviation, increases with increasing mean during the accumulation period. This dependency was characterized by the parameter $\beta$ (see Equation (2)) which was found to be similar for six seasons $(\beta \sim 0.84)$. The study thus implies that the point measurements capture the mean of HS less reliably when snow is accumulated in the Swiss Alps. It is further assumed that the observed development of the spatial distribution of HS is generated by the precipitation patterns from the Alpine microclimatological regions (Laternser, 2002; Scherrer and Appenzeller, 2006). Therefore, we hypothesize that at smaller scales, within the micrometeorological regions, the parameter $\beta$ might exhibit a smaller value due to a higher spatial homogeneity of precipitation originating from the Alpine meteorology.

In this study, we perform a scale analysis of $\beta$ during the accumulation period at scales between 10 and $300 \mathrm{~km}$ over the Swiss Alps, including a wider range of altitudes than in previous studies. The analysis is restricted to flat measuring sites without the use of spatially distributed modeling of the snow cover on complex Alpine topography. For a comparable quantification, we use two independent datasets representing flat-field HS estimations: (1) manual and automatic snow-depth point measurements from the operational snow-measuring network in the Swiss Alps, IMIS (Intercantonal Measurement and Information System; Rhyner and others, 2002), and (2) the snow precipitation output of the COSMO-7 (Consortium for Small-Scale Modelling) weather prediction model (see http://www.cosmo-model. org/) with a mesh size of $7 \mathrm{~km}$.

A further objective of our scale analysis is to quantify the dependency between the number of point measurements at a given scale and the accuracy of estimating the total snow amount (e.g. Famiglietti and others, 2008; Brocca and others, 2010). This relationship can help to validate spatially distributed snow models, different remote-sensing techniques or rain/snow precipitation radar, particularly with limited point measurement availability.

\section{DATA}

\subsection{Automatic and manual point measurements}

For the following scale analysis, 141 automatic and manual HS point measurement stations were used (Fig. 1, triangles), collecting data during seven winter periods from 2001/02 to $2007 / 08$. The stations are located on flat open terrain with minimal wind influence, defined as the standard for the 


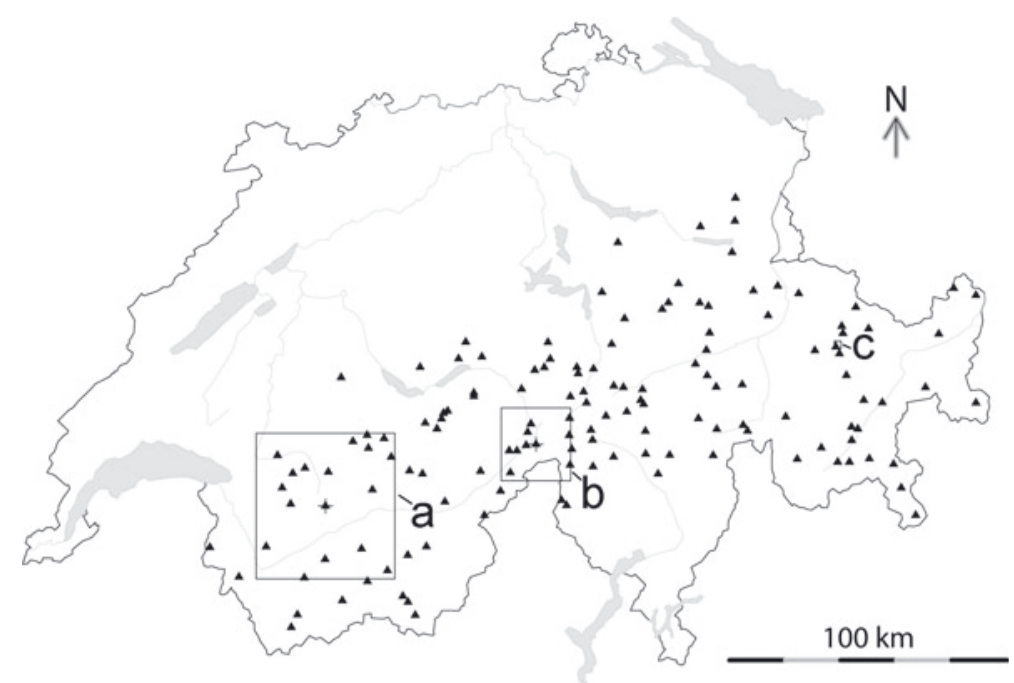

Fig. 1. Map of Switzerland with the locations of the 141 snow-depth measurement stations (triangles) covering the Swiss Alps. The squares indicate possible boxes of the sampling procedure for the scale analysis. Box a: $50 \mathrm{~km}$; box b: $25 \mathrm{~km}$; box c (Davos): $2.5 \mathrm{~km}$.

Swiss operational snow-measuring network, IMIS (Rhyner and others, 2002). The sites are considered representative of snow conditions within a region around the point measurements (Egli, 2008) and cover the Swiss Alpine region evenly, in both the vertical (800-2990 ma.s.I.) and the horizontal direction (about $100 \mathrm{~km} \times 300 \mathrm{~km}$ ).

The HS data were recorded at $30 \mathrm{~min}$ intervals and were aggregated to daily measurements by selecting the HS values at midnight. Manual snow-depth readings are read on a daily schedule $(\sim 0800 \mathrm{~h})$ from a snow stake at a flat measuring site located at lower altitudes in the vicinity of housing (Marty, 2008). All 141 snow-depth estimations were merged into a continuous dataset of daily HS measurement, while missing or erroneous values were carefully checked for plausibility and then interpolated and corrected manually.

\subsection{COSMO-7 model output data}

The numerical weather prediction model COSMO-7, operated by MeteoSwiss (http://www.meteoschweiz.admin. ch/web/en/research/consortia/cosmo.html), is a primitive equation model with nonhydrostatic, fully compressible dynamics. Among other meteorological parameters, COSMO-7 provides predictions of rain and snow precipitation on a regular grid of $7 \mathrm{~km}$ mesh size. It has been shown that generally the COSMO-7 model is able to represent daily snow precipitation (Egli and others, 2010). We used snow precipitation derived from the assimilation mode ( $w w w$. cosmo-model.org), representing the best current stage of the atmosphere of the model. From each COSMO-7 gridcell next to the locations of the 141 snow-depth measurements, daily snow precipitation output was extracted for the winter periods 2004/05, 2005/06 and 2006/07. The daily snow precipitation was cumulated from 1 November to 30 April. This period can generally be considered as the accumulation period of snow at high elevations in the Swiss Alps, but is not appropriate for lower elevations. The implications of this assumption are discussed further below. The summation of snow precipitation should reproduce the accumulation period of snow water equivalent as suggested by Egli and others (2009). Possible implications of this procedure are also discussed further below. Notably, the COSMO-7 output provided a different and independent dataset, where snow-depth point measurements on the ground were neither implicitly nor explicitly included.

\section{METHODS}

\subsection{Parameter $\beta$}

This study focuses on the development of the spatial variability of $\mathrm{HS}$ during the accumulation period only. The accumulation period was defined from the beginning of winter, where no snow is observed at all measuring sites, to the date when the mean of HS reached its seasonal maximum. We characterized the spatial variability of $\mathrm{HS}$ as the standard deviation:

$$
\sigma(x, t)=\sqrt{\frac{1}{N-1} \sum|x(t)-\overline{x(t)}|^{2}},
$$

where $x(t)$ is a HS reading for day $t$, and $\overline{x(t)}$ displays the spatial mean of $x$ over a sample of stations at a given date for measurements at the 141 stations and COSMO-7 gridpoints (in analogy to Egli and Jonas, 2009). Consequently, we also determined the relationship of the HS variability to the mean HS analogous to Egli and Jonas (2009):

$$
\sigma(\bar{x}) \sim \bar{x}^{\beta}
$$

where $\beta$ was determined by a least-squares fit to the exponential function. In the following, the relationship between mean and standard deviation of HS is characterized by the parameter $\beta$, indicating the development of the spatial variability of HS.

\subsection{Scale analysis and sampling procedure}

When analyzing smaller regions in the Swiss Alps, the number of available stations decreases with decreasing scale. Before implementing a sampling procedure for the scale analysis of $\beta$, we examined the number of stations sufficient to represent the standard deviation, $\sigma$, assuming no spatial structure of the snow-depth distribution. The closed circles in Figure 2 show the dependency of $\sigma$ on the number of samples calculated from a generated gamma distribution with a mean of 1 and a standard deviation of 1 . The gamma distribution of snow depths corresponds roughly to the distribution observed over the entire Swiss Alps at the 


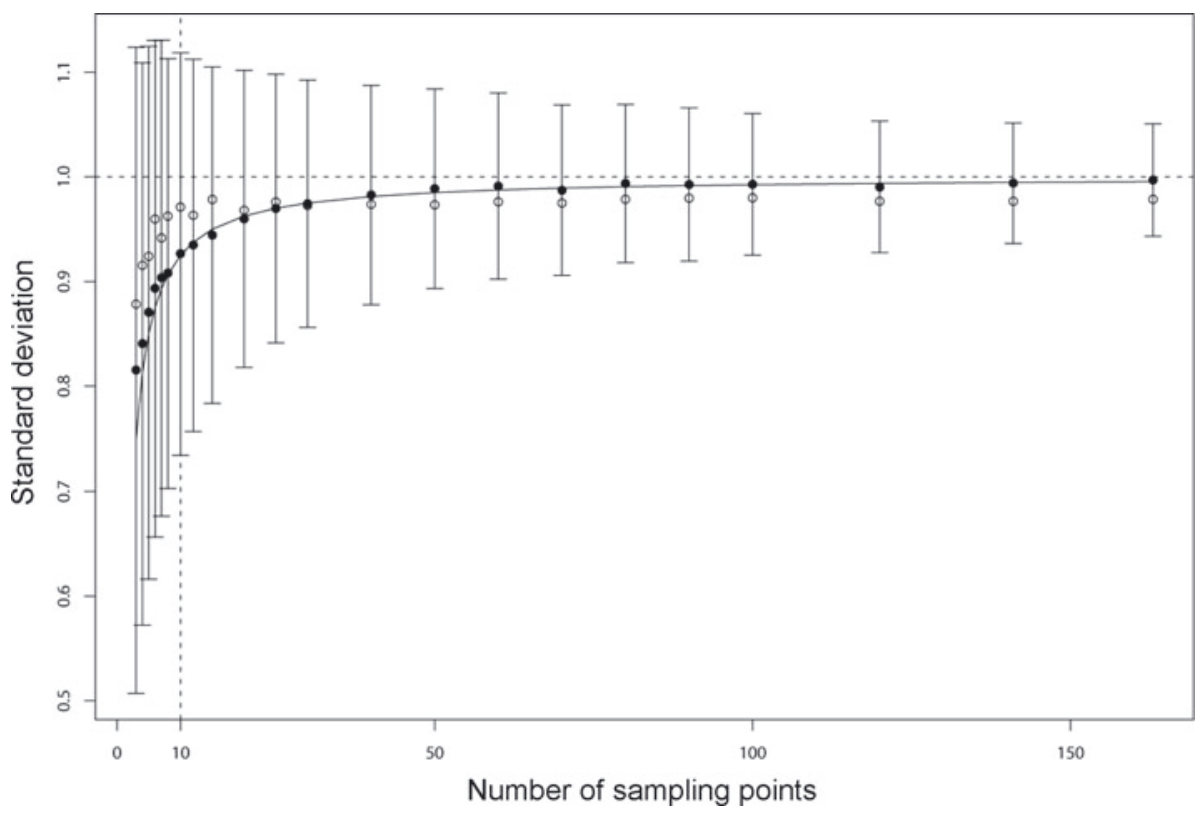

Fig. 2. Standard deviation as a biased estimator depending on the number of sampling points: simulated gamma distribution (closed circles) and $141 \mathrm{HS}$ measurements (open circles). Circles indicate the mean over 5000 realizations, where the error bars denote the deviation from the mean. The curve displays an approximation of the curve following Equation (4).

winter maximum. The open circles in Figure 2 display the same relationship calculated from the 141 existing HS measurements. Both curves show that the standard deviation is a biased estimator depending on the number of samples. In order to cover as small a scale as possible, ten sampling points (vertical dashed line in Fig. 2) were considered a good compromise to sample $\sigma$ sufficiently.

For the scale analysis of $\beta$, the following procedure was chosen: A scale $L$ is represented here by a spatial domain, from which station data are analyzed to calculate $\beta$. Such a domain can be centered around any of the snow stations and comprises a quadratic box of side length $L$. The following procedure was used to determine $\beta(L)$.

1. For a given scale, and a given snow station used as reference station, randomly select ten (different) stations located within the search domain centered around the reference station. This selection may or may not include the reference station.

2. Calculate $\beta$ based on Equation (2) and data from the ten stations selected above. If a search domain contains fewer than ten stations (which may happen at small scales), continue without calculating $\beta$.

3. Replicate steps 1 and 2 ten times for each of the 141 stations.

4. From these maximum $1410 \beta$ values, randomly select five (different) $\beta$ values and calculate the average.

5. Replicate step 4 a hundred times and calculate the mean of the averaged beta resulting in $\beta(L)$. The above averaging procedure (steps 4 and 5 ) has been set up to mitigate the scale-dependent number of $\beta$ values available after step 3 .

6. Replicate steps $1-5$ for each scale $L$ between 10 and $300 \mathrm{~km}$.

\section{RESULTS AND DISCUSSION}

\subsection{Scale analysis of $\beta$}

One objective here is to evaluate the initial hypothesis of decreasing $\beta$ with smaller scales. Figure 3 shows curves of standard deviation of HS over the mean of HS for four exemplary regions at different scales. Each point represents 1 day of the accumulation period during winter 2006/07 (Fig. $3 \mathrm{a}-\mathrm{c}$ ). The points are used to calculate $\beta$ following Equation (2), and to determine its regression (black lines). The values of $\beta$ in Figure 3 are almost equal, ranging from 0.836 to 0.907 , while their maximum mean snow depths differ depending on the sampled region. Note that Figure 3d displays a trajectory based on measurements captured in the region of Davos (Fig. 1, box c) during winter 2008/09. During this period, five stations were available in an area of about $1.2 \mathrm{~km} \times 2.6 \mathrm{~km}$, including stations from the Wannengrat test site (Grünewald and others, 2010). Although only five stations are included, the graph is additionally shown to demonstrate that the trajectory at a very small scale reflects behavior similar to the curves calculated from larger scales using ten stations (Fig. $3 \mathrm{a}-\mathrm{c}$ ).

Figure 4 displays $\beta$ as a function of scale for different examinations:

1. Point measurements using three stations $\left(\beta_{3}\right.$, circles $)$ and ten stations per box $\left(\beta_{10}\right.$, points).

2. Point measurements restricted to an elevation band between 1660 and $2990 \mathrm{ma.s.l}$. and ten samples per box ( $\beta_{\text {High, crosses). }}$

3. COSMO-7 data with ten samples per box ( $\beta_{\text {COSMO, }}$ triangles).

Each point represents the mean values of the sampling procedure over the analyzed seasons, where the single values deviate about $\pm 0.03\left(\beta_{10}, \beta_{\text {COSMO }}, \beta_{\text {High }}\right)$ and \pm 0.06 $\left(\beta_{3}\right)$ from the mean. Figure 4 reveals that $\beta$ exhibits similar values for scales down to 25,10 or even $2.5 \mathrm{~km}$ as is 


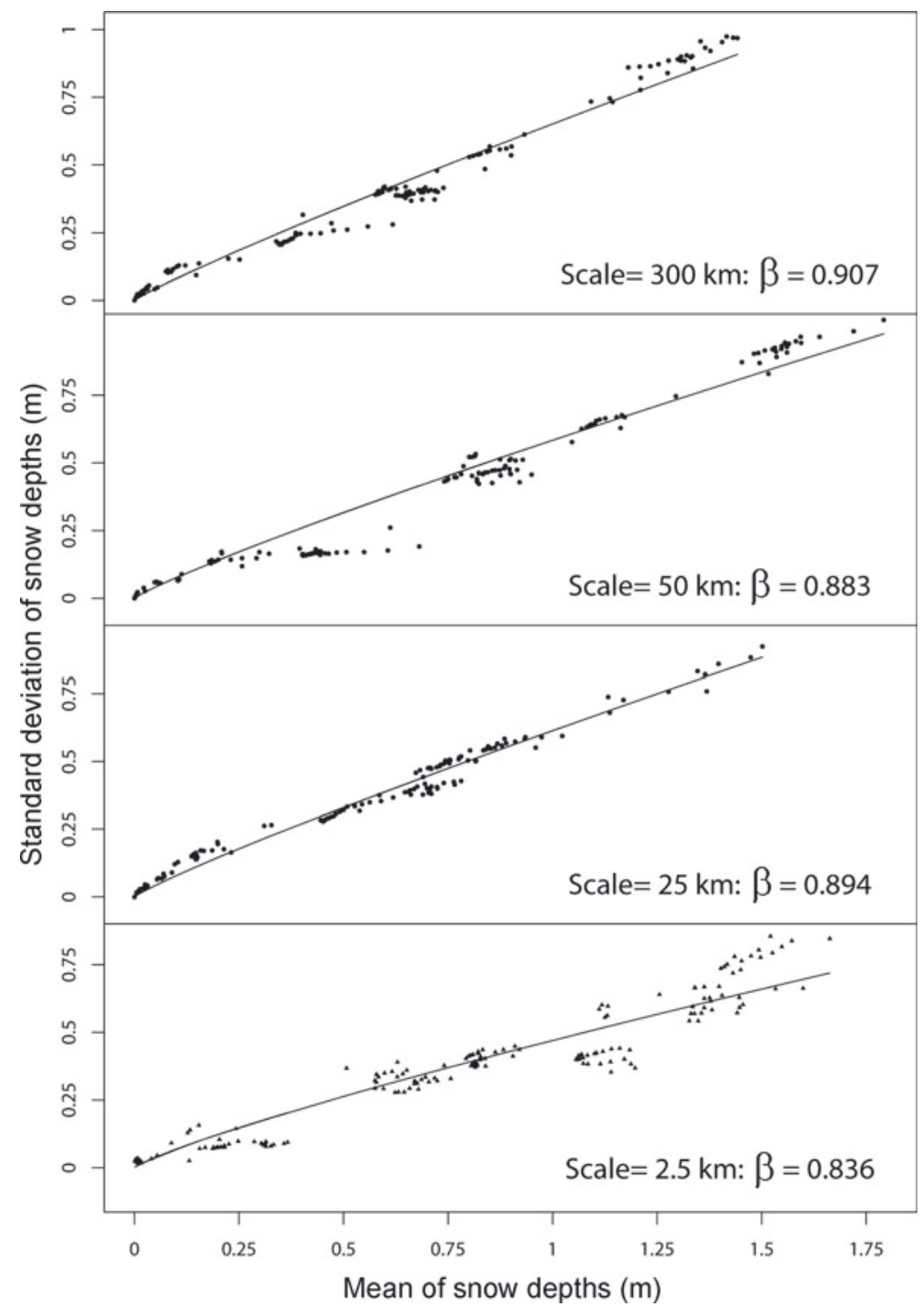

Fig. 3. Trajectories of standard deviation over mean of HS at different scales in the Swiss Alps. The lines indicate the least-squares fit of Equation (2). (a-c) include ten stations from (a) the entire Swiss Alps, (b) a box of $50 \mathrm{~km}$ side length and (c) a $25 \mathrm{~km}$ box. (d) The trajectory based on measurements in the Davos region.

observed at the scale of the entire Swiss Alps $(300 \mathrm{~km})$. Note that the scale-invariant behavior of $\beta$ is similar when analyzing each season separately (data not shown). This effect is rather astonishing as it is assumed (Egli and Jonas, 2009) that $\beta$ for the entire Swiss Alps is formed by the Alpine microclimatological precipitation pattern (Laternser, 2002). The results of an analysis of $\beta$ for each individual climatological region proposed by Laternser (2002) reveal that $\beta_{\text {Clim.Region }}$ did not substantially deviate from the $\beta$ of the entire Swiss Alps (specific table not shown). This finding, and especially the results in Figures 3 and 4, may suggest that the spatial variability of HS is not only formed by the large-scale precipitation patterns but also perhaps mainly by other processes at smaller scales, even smaller than those analyzed in this study. These processes may include various snow distribution processes on smaller scales (Balk and Elder, 2000), such as preferential deposition of snow (Lehning and others 2008) and wind drift (e.g. Liston and Sturm, 1998). At these smaller scales, the roughness of the terrain surface becomes an increasingly dominating factor. For this reason, it could be assumed that the effect of increasing snow-depth variability with increasing mean snow cover observed at very large scales may be affected exclusively by the small-scale processes. This would imply that the snow-depth point measurements represent the snow cover exclusively very locally and do not represent a larger region around the measuring site as assumed (see section 2; Egli, 2008).

To evaluate whether the scaling invariance of $\beta$ is caused by small-scale processes or by the large-scale precipitation patterns, we analyzed the independent dataset of COSMO7. Note that COSMO-7 estimates the snow precipitation on a mesh of $7 \mathrm{~km}$ and does not account for small-scale processes below that size. Moreover, the physical processes of the model may be more appropriately reproduced by a couple of points of the regular mesh (e.g. scale of $\sim 35 \mathrm{~km}$ ), rather than a single gridpoint. The results in Figure 4 reveal that this additional dataset shows an almost constant scaling behavior of $\beta_{\text {COSMO }}$ at scales from 300 to $50 \mathrm{~km}$, as well as, for example, $\beta_{10}$. However, $\beta_{\text {COSMO }}$ exhibits a smaller value than $\beta_{10}$. This deviation can be explained by the fact that COSMO-7 represents cumulated snow precipitation and does not account for the processes of melting or sublimation during the accumulation period. Particularly at lower 


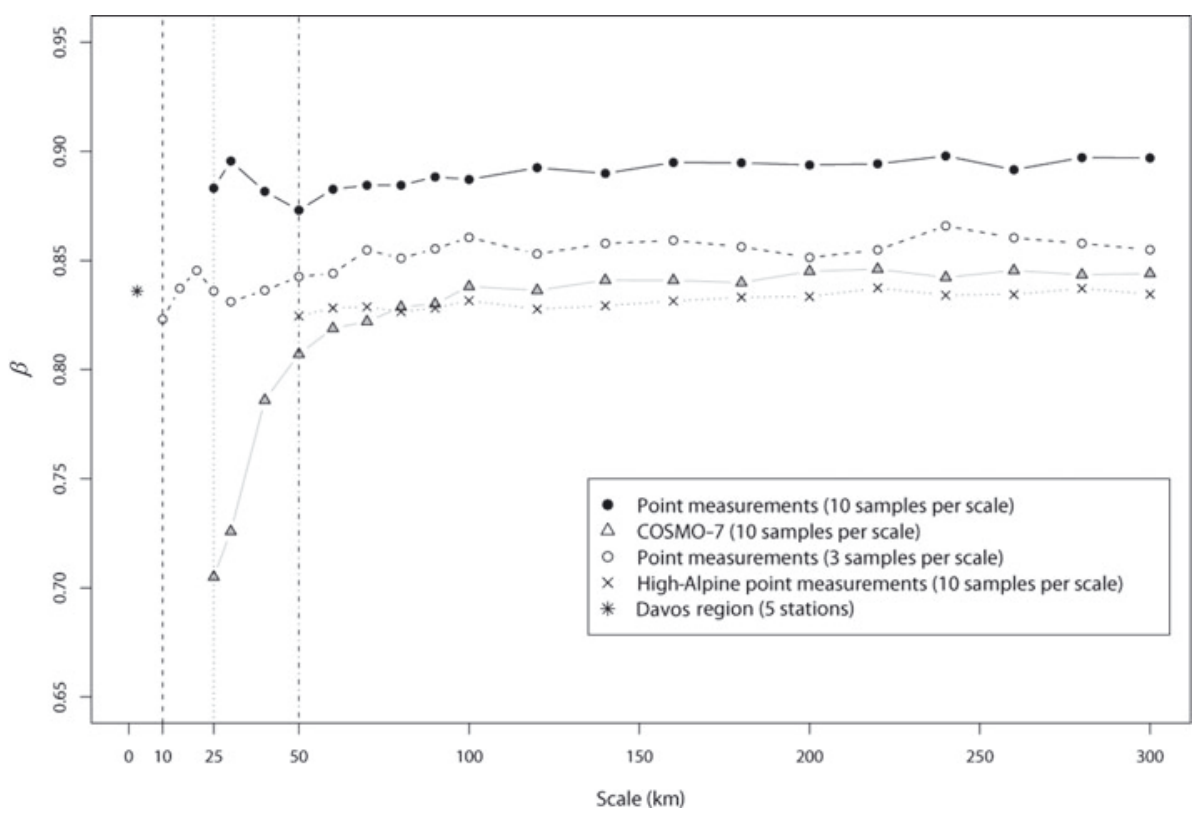

Fig. 4. Scale analysis of $\beta$ for two data sources (point measurements and COSMO-7), for an elevation band between 1660 and $2990 \mathrm{~m}$ a.s.I. and for different numbers of stations (three and ten) used for the scale analysis. The star denotes $\beta$ determined by five stations located in the Davos region at a scale of $2.5 \mathrm{~km}$.

altitudes, the accumulation period is affected by melting cycles, resulting in a generally smaller snow depth (Laternser, 2002). This suggests that the assumption of a strict accumulation period between 1 November and 30 April is not appropriate for lower elevations. However, when the analysis of $\beta$ is restricted to high-Alpine regions, where only snow accumulation can be assumed, $\beta_{\text {High }}$ reaches scale-invariant values of $\beta_{\text {High }} \sim 0.83$, which is close to $\beta_{\text {COSMO }} \sim 0.84$ (see Fig. 4). At the scale of $300 \mathrm{~km}$ $\beta_{\text {High }} \sim 0.83$ is comparable to $\beta \sim 0.84$ reported by Egli and Jonas (2009), who analyzed snow depths in the same elevation bands for that scale. The study further stated that, at high-Alpine elevations, melting or sublimation is insignificant for the mass balance during the accumulation phase. Therefore, cumulated COSMO-7 snow precipitation data reflect the total amount of snow water equivalent (SWE) during the accumulation period. The similar values of $\beta_{\text {COSMO }}$ and $\beta_{\text {High }}$ suggest that the scale analysis obtained here for snow depths may also be applied for SWE, at least for high-Alpine sites. This is in line with the findings of Sturm and others (2010) where $90 \%$ of the variance of SWE can be explained by the variance of HS.

When analyzing the parameter $\beta$ for different elevation bands separately, the same scale invariance can be found. However, the absolute value of $\beta$ restricted to an elevation band differs slightly from $\beta$ including the entire range of elevation. At the lowest elevation band, 800-1100 m a.s.l., $\beta \sim 0.87$ exhibits the highest increase in snow-depth variability with increasing mean due to overlapping melting and accumulation cycles. However, in higher elevation bands (e.g. 1600-2100 ma.s.I.), $\beta$ decreases, reaching its lowest value, and increases again when restricted to high-Alpine elevations, $\beta_{\text {High, }}$ which can also be found with $\beta_{\text {COSMO }}$. Because $\beta_{\text {COSMO }}$ does not include the process of melting, the difference of altitudinal bands cannot be observed in the analysis of $\beta_{\text {COSMO. }}$

We conclude that at high-Alpine sites, the spatial variability of HS at scales between 50 and $300 \mathrm{~km}$ stems from the precipitation pattern of the Alpine microclimatological regions. At scales between 25 and $50 \mathrm{~km}, \beta_{\text {COSMO }}$ decays rapidly, which may be attributed to technical aspects of the model itself, where neighboring gridcells may not deviate as much as observed on the ground and only a couple of gridpoints may be able to represent the physical processes adequately. However, for the point measurements, $\beta_{3}$ and $\beta_{10}$ remain scale-invariant until 25 and $10 \mathrm{~km}$ (or even $2.5 \mathrm{~km}$; Fig. 3d), which may stem from small-scale precipitation patterns or from small-scale processes near the snow surface. At these scales, we cannot determine from which processes the increasing variability with increasing mean may stem. Nevertheless, the quantification of $\beta$ determined here and its scaleinvariant behavior may help to provide a small-scale subpixel parameterization of a distributed snow model. Particularly for a stochastic model approach, where the mean and the standard deviation of the probability density function (PDF) are needed (e.g. Luce and others, 1999; Liston, 2004; Perona and others, 2007), the quantitative evaluation of $\beta$ for different scales may be helpful.

\subsection{Accuracy of estimating the mean of snow cover}

The second objective of this study addresses the question: how accurately can we estimate the total snow amount at a given scale using a small number of flat-field snow-depth measurements? The results in Figures 3 and 4 show that the standard deviation increases with increasing mean quantitatively similarly for scales between 10 and $300 \mathrm{~km}$ with an exponent $\beta \sim 0.9$ considering sites at 800-2990 ma.s.l. This means that the uncertainty of estimating the mean snow depths is increasing if the number of stations is constant during the accumulation period. Conversely, to obtain absolute accuracy in the capture of mean snow depths, more HS point measurements are needed the more snow is accumulated in a given region. Generally, the absolute accuracy of a measurement depends on the number of sampling points, $N$, and the standard deviation, 


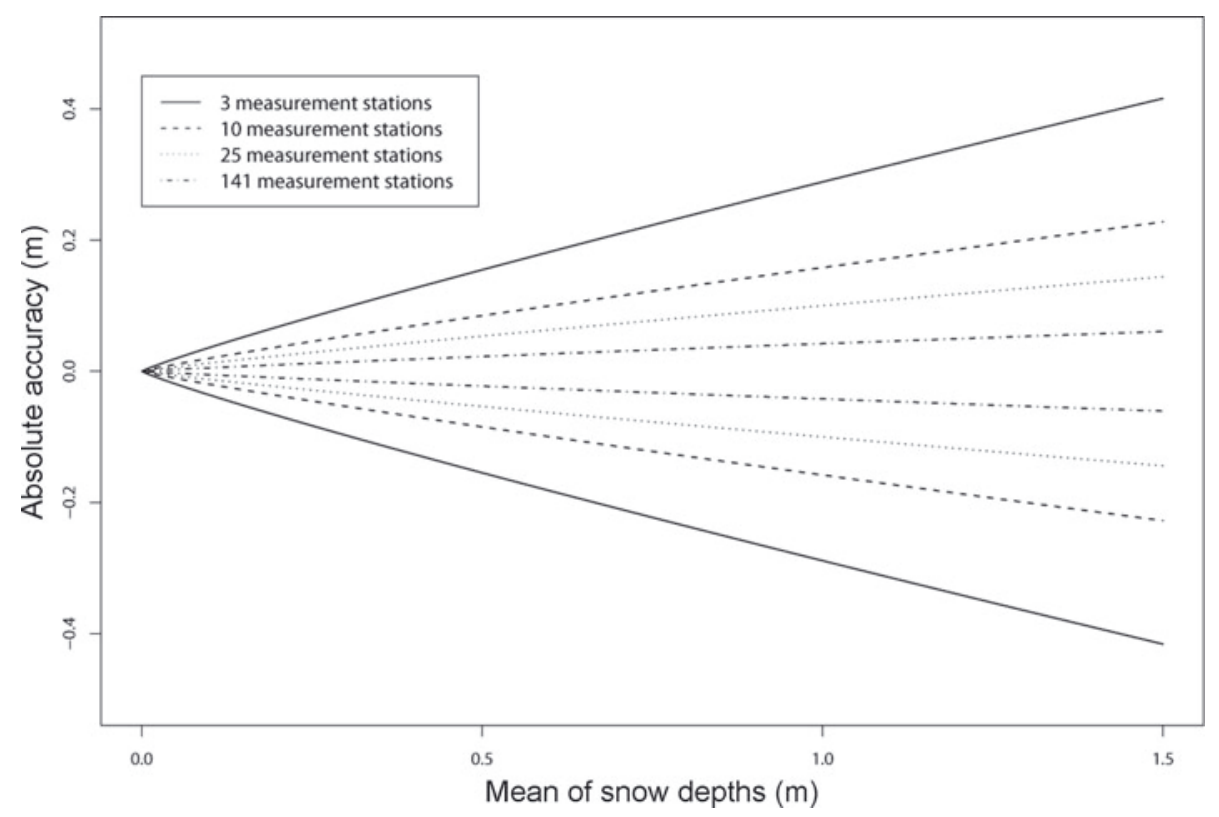

Fig. 5. Absolute accuracy of mean snow-depth estimations depending on the number of point measurements.

$\sigma$, given by

$$
\text { absolute accuracy }= \pm \frac{1}{2} \frac{\sigma}{\sqrt{N}}
$$

The standard deviation of snow depths in the Swiss Alps depends on the mean following Equation (2). Therefore the absolute accuracy is given by

$$
\text { absolute accuracy }= \pm \frac{1}{2} \frac{\bar{x}^{\beta}}{\sqrt{N}},
$$

where $\beta$ is scale-invariant at scales from 10 to $300 \mathrm{~km}$. The results in Figure 4 can now be applied using Equation (3) to evaluate the minimum number of sampling points required to obtain a certain confidence interval (Brocca and others, 2010) for the estimate of the total snow amount in a considered area. Figure 5 shows the absolute accuracy for various numbers of samples following Equation (3) $(\beta \sim 0.9)$. The relationship in Figure 5 is of practical importance for ground truth verifications of remote-sensing techniques and for the validation of spatially distributed snow models, particularly when limited data are available (Famiglietti and others, 2008).

Figure 4 shows $\beta$ calculated from 141 point measurements but with only three samples per scale $\left(\beta_{3}\right)$. Due to this smaller number of samples, a scale analysis can be provided down to $10 \mathrm{~km}$. However, as the standard deviation is a biased estimator (Fig. 2), $\beta_{3}$ is smaller $(\sim 0.85)$ than $\beta_{10}$. The bias of the standard deviation can be approximately quantified by (Kenney and Keeping, 1951; http://mathworld. wolfram.com/StandardDeviationDistribution.html):

$$
\sigma_{\text {observed }}=\sigma_{\text {real }}\left(1-\frac{3}{4 N}\right),
$$

where $N$ is the number of sampling points. The curve in Figure 2 shows Equation (4) and indicates that this approximation fits the observed relationship well. The results of $\beta$ (Fig. 4) and its relationship in Equation (2) may be used to analyze fewer point measurements for plausibility and to correct the obtained standard deviation to a value closer to the expected real value. This correction has further practical implications in snow hydrology, where the development of the snow-covered area during the ablation period is strongly linked to the spatial distribution of snow cover at the end of the accumulation period (see Egli and Jonas, 2009). In particular, the development of the fractional snow-covered area during melt is determined by the PDF of the snow distribution and its standard deviation before melt starts (e.g. Luce and others, 1999; Essery and Pomeroy, 2004).

\section{CONCLUSIONS AND OUTLOOK}

The relationship between the total amount of snow and its variability during the accumulation period is observed to be similar at scales between 10 and $300 \mathrm{~km}$ in the Swiss Alps. The variability of snow depth is quantified in terms of standard deviation over mean of snow depth. This scaleinvariant relationship can be applied for a subpixel parameterization of distributed snow models and for a stochastic modeling approach of snow distribution, where the mean and standard deviation of the PDF are needed.

The absolute accuracy of the total snow content depends on the averaged snow depths and on the sampling scheme, i.e. numbers of stations available to estimate the mean of accumulated snow. We quantified the absolute accuracy at different scales, which can be applied to validate different spatially distributed snow models or remote-sensing techniques.

We also showed that the numerical weather prediction model COSMO-7 reproduced the same scale invariance of the relationship of mean cumulated snow precipitation and its standard deviation for scales between 50 and $300 \mathrm{~km}$. This suggests that the variability of snow depths at these scales stems from the meteorological precipitation patterns in the Swiss Alps. However, at scales between 10 and $50 \mathrm{~km}$ the observed variability may either originate from smallscale precipitation patterns or from other small-scale processes influencing the snow cover on the ground. Future work may investigate the development of snow depth or cumulated precipitation variability at these scales. Tools 
such as high-resolution precipitation radar or physically based snow-cover models could be used.

\section{ACKNOWLEDGEMENTS}

We thank J.M. Bettems and F. Schubiger of MeteoSwiss for their support for the COSMO-7 data acquisition and processing, and two anonymous reviewers and A. Ohmura for constructive suggestions that helped to improve the manuscript.

\section{REFERENCES}

Balk, B. and K. Elder. 2000. Combining binary decision tree and geostatistical methods to estimate snow distribution in a mountain watershed. Water Resour. Res., 36(1), 13-26.

Brocca, L., F. Melone, T. Moramarco and R. Morbidelli. 2010. Spatial-temporal variability of soil moisture and its estimation across scales. Water Resour. Res., 46(W2), W02516. (10.1029/ 2009WR008016.

DeWalle, D.R. and A. Rango. 2008. Principles of snow hydrology. Cambridge, etc., Cambridge University Press.

Egli, L. 2008. Spatial variability of new snow amounts derived from a dense network of Alpine automatic stations. Ann. Glaciol., 49, 51-55.

Egli, L. and T. Jonas. 2009. Hysteretic dynamics of seasonal snow depth distribution in the Swiss Alps. Geophys. Res. Lett., 36(2), L02501. (10.1029/2008GL035545.)

Egli, L., T. Jonas and R. Meister. 2009. Comparison of different automatic methods for estimating snow water equivalent. Cold Reg. Sci. Technol., 57(2-3), 107-115.

Egli, L., T. Jonas and J.-M. Bettems. 2010. A virtual network for estimating daily new snow water equivalent and snow depth in the Swiss Alps. Ann. Glaciol., 51(54), 32-38.

Erxleben, J., K. Elder and R. Davis. 2002. Comparison of spatial interpolation methods for estimating snow distribution in the Colorado Rocky Mountains. Hydrol. Process., 16(18), 3627-3649.

Essery, R. and J. Pomeroy. 2004. Implications of spatial distributions of snow mass and melt rate for snow-cover depletion: theoretical considerations. Ann. Glaciol., 38, 261-265.

Famiglietti, J.S., D. Ryu, A.A. Berg, M. Rodell and T.J. Jackson. 2008. Field observations of soil moisture variability across scales. Water Resour. Res., 44(W1), W01423. (10.1029/ 2006WR005804.)

Grünewald, T., M. Schirmer, R. Mott and M. Lehning. 2010. Spatial and temporal variability of snow depth and ablation rates in a small mountain catchment. Cryosphere, 4(2), 215-225.
Jonas, T., C. Marty and J. Magnusson. 2009. Estimating the snow water equivalent from snow depth measurements in the Swiss Alps. J. Hydrol., 378(1-2), 161-167.

Kenney, J.F. and E.S. Keeping. 1951. The distribution of the standard deviation. In Kenney, J.F. and E.S. Keeping, eds. Mathematics of statistics, Part 2. Princeton, NJ, D. van Nostrand, 170-173.

Laternser, M. 2002. Snow and avalanche climatology of Switzerland. (PhD thesis, ETH Zürich.)

Lehning, M., I. Völksch, D. Gustafsson, T.A. Nguyen, M. Stähli and M. Zappa. 2006. ALPINE3D: a detailed model of mountain surface processes and its application to snow hydrology. Hydrol. Process., 20(10), 2111-2128.

Lehning, M., H. Löwe, M. Ryser and N. Radeschall. 2008. Inhomogeneous precipitation distribution and snow transport in steep terrain. Water Resour. Res., 44(W7), W07404. (10.1029/2007WR006545.)

Liston, G.E. 2004. Representing subgrid snow cover heterogeneities in regional and global models. J. Climate, 17(6), 1381-1397.

Liston, G.E. and M. Sturm. 1998. A snow-transport model for complex terrain. J. Glaciol., 44(148), 498-516.

Luce, C.H., D.G. Tarboton and K.R. Cooley. 1999. Sub-grid parameterization of snow distribution for an energy and mass balance snow cover model. Hydrol. Process., 13(12-13), 1921-1933.

Marty, C. 2008. Regime shift of snow days in Switzerland. Geophys. Res. Lett., 35(12), L12501. (10.1029/2008GL033998.)

McClung, D.M. and P.A. Schaerer. 1993. The avalanche handbook. Seattle, WA, The Mountaineers.

Perona, P., A. Porporato and L. Ridolfi. 2007. A stochastic process for the interannual snow storage and melting dynamics. J. Geophys. Res., 112(D8), D08107. (10.1029/2006JD007798.)

Rhyner, J. and 7 others. 2002. Avalanche warning Switzerland: consequences of the avalanche winter 1999. In Stevens, J.R., ed. Proceedings of the International Snow Science Workshop, 30 September-3 October 2002, Penticton, British Columbia. Victoria, B.C., British Columbia Ministry of Transportation. Snow Avalanche Programs

Scherrer, S.C. and C. Appenzeller. 2006. Swiss Alpine snow pack variability: major patterns and links to local climate and largescale flow. Climate Res., 32(3), 187-199.

Seidel, K. and J. Martinec. 2004. Remote sensing in snow hydrology: runoff modelling, effect of climate change. Berlin, etc., Springer-Praxis.

Shook, K. and D.M. Gray. 1996. Small-scale spatial structure of shallow snowcovers. Hydrol. Process., 10(10), 1283-1292.

Sturm, M., B. Taras, G.E. Liston, C. Derksen, T. Jonas and J. Lea. 2010. Estimating snow water equivalent using snow depth data and climate classes. J. Hydromet., 11(6), 1380-1394. 